\title{
HUBUNGAN TINGKAT STRESS DENGAN KEPUASAN KERJA PADA MASINIS PT KERETA API INDONESIA DI UPT CREW SEMARANG PONCOL
}

\author{
Taufiq Annas, Susi Nurhayati \\ STIKes Karya Husada Semarang
}

\begin{abstract}
ABSTRAK
Tingkat stres kerja berlebihan dapat berdampak negatif terhadap prestasi kerja karyawan PT. KAI yang pada akhirnya dapat merugikan perusahaan. Apalagi jika stres kerja tersebut berada dalam taraf tinggi tentu akan memberikan dampak negatif. Tujuan penelitian ini adalah mengetahui hubungan antara stress kerja dengan kepuasan kerja pada masinis PT Kereta Api Indonesia di UPT Crew Semarang Poncol. Jenis penelitian adalah korelasi dengan pendekatan cross sectional. Populasi dalam penelitian ini adalah seluruh masinis PT Kereta Api Indonesia UPT Crew Semarang Poncol sejumlah 223 orang. Teknik sampling yang digunakan adalah accidental sampling dengan jumlah 143 orang. Hasil penelitian didapatkan bahwa tingkat stres kerja yang dialami oleh responden sebagian besar adalah tinggi yaitu sebanyak 67,1\%. Kepuasan kerja responden sebagian besar dalam kategori tidak puas yaitu sebanyak 78 orang (54,5\%). Ada hubungan antara tingkat stress dengan kepuasan kerja pada masinis PT Kereta Api Indonesia di UPT Crew Semarang Poncol.Berdasarkan hasil tersebut PTKAI diharapkan dapat menambah jumlah masinis dengan pola shift kerja yang longgar sehingga masinis memiliki waktu isirahat yang cukup untuk mengurangi stress akibat jadwal kerja yang padat.
\end{abstract}

Kata kunci : Stres Kerja, Kepuasan Kerja.

\section{STRESS LEVEL RELATIONSHIP WITH JOB SATISFACTIONAT INDONESIAN PT TRAIN ENGINEERING AT UPT CREW SEMARANG PONCOL}

Excessive work stress levels can have a negative impact on employee performance at PT. KAI which in the end can harm the company. Moreover, if the work stress is at a high level, it will certainly have a negative impact. The purpose of this study was to determine the relationship between job stress and job satisfaction at PT Kereta Api Indonesia machinists at UPT Crew Semarang Poncol. This type of research is correlation with cross sectional approach. The population in this study were all engineers of PT Kereta Api Indonesia UPT Crew Semarang Poncol totaling 223 people. The sampling technique used is accidental sampling with a total of 143 people. The results showed that the level of work stress experienced by most of the respondents was high as much as 67.1\%. Most of the respondents' job satisfaction was in the dissatisfied category as many as 78 people (54.5\%). There is a relationship between stress levels and job satisfaction at PT Kereta Api Indonesia's machinists at UPT Crew Semarang Poncol. Based on these results PTKAI is expected to increase the number of drivers with a loose work shift pattern so that the machinists have sufficient rest time to reduce stress due to a busy work schedule. .

Keywords: Job Stress, Job Satisfaction. 


\section{PENDAHULUAN}

Pekerjaan merupakan bagian yang memegang peranan penting bagi kehidupan manusia, yaitu dapat memberikan kepuasan, tantangan, bahkan dapat pula menjadi gangguan dan ancaman. Gangguan gangguan kesehatan terjadi akibat lingkungan kerja fisik yang buruk telah diketahui, desain dan organisasi kerja yang tidak memadai, seperti kecepatan dan beban kerja yang berlebihan, merupakan faktor- faktor yang dapat menimbulkan gangguan kesehatan akibat kerja.

Penerapan keselamatan dan kesehatan kerja akan menjamin dilaksanakannya semua peraturan perundangan keselamatan dan kesehatan kerja yang ada, dengan melaksanakan pengendalian risiko bahaya yang ada di tempat kerja (Setyawati, 2010). Undang-undang No. 36 tahun 2009 tentang Kesehatan pasal 164 ayat 4 menjelaskan bahwa upaya kesehatan kerja ditujukan untuk melindungi pekerja agar hidup sehat dan terbebas dari gangguan kesehatan serta pengaruh buruk yang diakibatkan oleh pekerjaan.

Terciptanya keselamatan dan kesehatan kerja akan mampu memberikaan kepada pekerja merasakan kepuasan, kenyamanan, dan kebahagiaan di dalam pekerjaan. Tetapi kenyataan yang dihadapi adalah banyak pekerja yang berdasarkan berbagai macam hasil penelitian menunjukkan bahwa pekerja mengalami stres kerja. Stres kerja dapat terjadi ketika individu-individu tersebut dituntut lebih banyak menciptakan keunggulan kompetitif melalui peningkatan pengetahuan, pengalaman, keahlian dan komitmen serta hubungan dengan rekan sekerja maupun pihak lain di luar perusahaan (Stranks, 2007).

Akar persoalan kinerja pada faktor manusia tersebut juga terjadi pada masalah sistem dan tata kelola ketenagakerjaan di PT KAI (Yuhans, 2010). Kondisi ini terlihat dari perhatian manajemen yang masih kurang terhadap beban kerja dan hak-hak normatif karyawan PT KAI seperti masalah pembagian shift, tekanan waktu, kesejahteraan pegawai, sistem teknologi dan informasi yang masih terbatas seperti system informasi dan komunikasi untuk pegawai kereta api front liner (masinis, PPKA, teknisi lokomotif dan gerbong, serta teknisi persinyalan dan emplasemen stasiun). Masalah-masalah pengembangan sistem dan tata kelola ketenagakerjaan, serta beban atau tuntutan pekerjaan yang tinggi pada pegawai bagian SDM PT. KAI merupakan tugas kerja yang harus diselesaikan oleh pegawai bagian SDM. tulah yang dapat menyebabkan stres kerja (Yuhans, 2010).

Permasalahan yang dihadapi oleh PT KAI ini salah satunya adalah masih tingginya angka kecelakaan kereta api yang berdasarkan data tahun 2013 ditemukan KRL 456 anjlok akibat permasalah teknis di Stasiun Bojonegoro, tahun 2014 KA 7118 
Pangrango anjlok akibat permasalahan teknis di Cicurug, KA Siliwangi anjlok akibat permasalahan teknis di Stasiun Cianjur. Berdasarkan data dari tahun 1994-2014 diketahui bahwa sebagian besar kecelakaan kereta terjadi karena anljok sebesar 23 dari 41 kejadian (Laporan tahunan PT KAI, 2012).

Tingkat stres kerja berlebihan dapat berdampak negatif terhadap prestasi kerja karyawan PT. KAI yang pada akhirnya dapat merugikan perusahaan. Apalagi jika stres kerja tersebut berada dalam taraf tinggi tentu akan memberikan dampak negatif. Dampak negatif tersebut dapat berupa rendahnya tingkat produktivitas, minimnya kreativitas, kurangnya motivasi, pengambilan keputusan yang tidak efektif, kualitas komunikasi antar karyawan yang rendah, tingkat absensi atau ketidakhadiran pegawai yang tinggi, bahkan munculnya tindakan kekerasan dalam lingkungan kerja (Stranks, 2007).

Stres kerja yang tinggi dapat berdampak pada kepuasan kerja. Robin (2007) menyatakan bahwa dampak stress kerja dapat berpengaruh langsung terhadap kepuasan kerja. Ketegangan yang terkait dengan pekerjaan cenderung mengurangi kepuasan kerja secara menyeluruh, meskipun stress tingkat rendah sampai sedang mungkin dapat memperbaiki kinerja namun stress kerja tetap menciptakan suasana yang tidak menyenangkan terhadap bagi pekerja.

Kepuasan kerja sangatlah penting sebab karyawan dalam sebuah organisasi merupakan factor yang paling dominan dalam menentukan berhasil atau tidaknya kegiatan organisasi tersebut. Kepuasan kerja karyawan harus diciptakan sebaik-baiknya agar moral kerja, dedikasi, kecintaan dan kedisiplinan kerja tinggi. PT KAI (Kereta Api Indonesia) menuntut karyawannya untuk mengutamakan pelayanan dan keselamatan pada konsumen (Yuhans, 2010). Di sisi lain, kinerja karyawan PT. KAI sering disorot karena dalam satu dekade terakhir ini sering terjadi kecelakaan yang merenggut nyawa manusia hingga ratusan jiwa. Berdasarkan data dari tahun 1994-2014 sekitar 420 korban meninggal dan

600 korban luka berat akibat 42 kejadian kecelakaan kereta (articles.portal-tol.net).

Data dari PT Kereta Api Indonesia di UPT Crew Semarang Poncol setiap hari jumlah masinis yang melakukan pemeriksaan kesehatan di stasiun ini mencapai sekitar 100 orang setiap harinya. Berdasarkan survey pendahuluan yang dilakukan pada tanggal 18 Maret 2015 melalui wawancara dengan 10 
orang masinis yang ada di Stasion Poncol Semarang menemukan bahwa semua masinis ini mengeluhkan beban kerja yang tinggi. Masinis mengeluhkan jam istirahat yang kurang terutama pada masinis yang bertempat tinggal jauh dari stasiun, karena waktu untuk istirahat sudah terpotong untuk perjalanan. Sementara itu beban pekerjaan yang tinggi karena setiap hari harus mengoperasikan kereta api untuk melayani penumpang dan hanya mendapat libur satu hari dalam satu minggu, bahkan para masinis ini juga harus bekerja melebihi 8 jam kerja sehari karena suatu hal seperti keterlambatan jadwal kereta dan sebagainya. Beban kerja yang tinggi ini yang berlangsung terus menerus menyebabkan masinis merasa stress, dan dikhawatirkan akan mempengaruhi kepuasan kerjanya yang pada akhirnya berpengaruh terhadap kinerja masinis.

\section{METODE PENELITIAN}

Jenis Penelitian ini adalah deskriptif korelasi. Desain penelitian yang digunakan adalah cross sectional. Populasi dalam penelitian ini adalah seluruh masinis PT Kereta Api Indonesia UPT Crew Semarang Poncol sejumlah 223 orang. Teknik sampling dalam penelitian ini adalah accidental sampling yaitu pengambilan sampel secara kebetulan ditemui pada saat penelitian (Arikunto, 2006). Jumlah sampel penelitian 143 orang. Analisis bivariat yang digunakan dalam penelitian ini adalah Chi Square.

\section{HASIL DAN PEMBAHASAN}

A. Hasil

Tabel 1. Distribusi Frekuensi Responden Berdasarkan Stres Kerja

\begin{tabular}{lcc}
\hline \multicolumn{1}{c}{ Stres Kerja } & Frekuensi & Persentase \\
\hline Rendah & 47 & 32,9 \\
Tinggi & 96 & 67,1 \\
\hline Jumlah & 143 & 100 \\
\hline
\end{tabular}

Berdasarkan bahwa sebagian besar tingkat stres kerja yang dialami oleh responden adalah tinggi yaitu sebanyak 96 orang $(67,1 \%)$, dan yang rendah sebanyak 47 orang $(32,9 \%)$. 
Tabel 2 Distribusi Frekuensi Responden Berdasarkan kepuasan kerja

\begin{tabular}{lcc}
\hline \multicolumn{1}{c}{ Kepuasan Kerja } & Frekuensi & Persentase \\
\hline Tidak puas & 78 & 54,5 \\
Puas & 65 & 45,5 \\
\hline Jumlah & 143 & 100 \\
\hline
\end{tabular}

Berdasarkan table 2 diketahui bahwa sebagian besar kepuasan kerja responden dalam kategori tidak puas yaitu sebanyak 78 orang (54,5\%), dan yang puas sebanyak 65 orang $(45,5 \%)$.

Tabel 3. Hubungan antara tingkat stress dan kepuasan kerja

\begin{tabular}{|c|c|c|c|c|c|c|c|}
\hline \multirow[t]{2}{*}{ Stres } & \multicolumn{4}{|c|}{ Kepuasan Kerja } & \multirow[t]{2}{*}{ Total } & \multirow[t]{2}{*}{$\%$} & \multirow{2}{*}{$\begin{array}{c}\mathrm{P} \\
\text { value }\end{array}$} \\
\hline & Tidak puas & $\%$ & Puas & $\%$ & & & \\
\hline Rendah & 0 & 0,0 & 47 & 100 & 47 & 100 & \multirow{2}{*}{0,000} \\
\hline Tinggi & 78 & 52,4 & 18 & 18,8 & 96 & 100 & \\
\hline Jumlah & 78 & 52,4 & 65 & 45,5 & 100 & 100 & \\
\hline
\end{tabular}

Berdasarkan hasil analisis statistik menunjukkan bahwa dari 47 responden yang stresnya rendah seluruhnya menyatakan kepuasan kerjanya puas yaitu sebanyak 100,0\%. Responden yang stresnya tinggi sebagian besar kepuasan kerjanya menyatakan tidak puas yaitu sebanyak 52,4\%. Berdasarkan uji chi square didapatkan nilai p sebesar 0,000 $<0,05$ sehingga dinyatakan ada hubungan yang bermakna antara tingkat stress dengan kepuasan kerja pada masinis PT Kereta Api Indonesia di UPT Crew Semarang Poncol.

\section{B. PEMBAHASAN}

Berdasarkan hasil penelitian menunjukkan bahwa sebagian besar tingkat stress kerja yang dialami oleh responden adalah tinggi yaitu sebanyak 67,1\% dan yang rendah sebanyak 32,9\%. Stres kerja ini terjadi akibat ritme kerja yang monoton dan jam kerja yang tinggi sehingga menyebabkan kelelahan.

Stres merupakan dampak penting dari interaksi antara pekerjaan dan individu. Stres dalam konteks ini adalah keadaan tidak seimbang dalam diri seorang individu yang sering kali termanifestasi lewat gejala seperti insomnia, keringat berlebihan, gugup dan tidak tenang. Apakah stres merupakan hal yang positif atau negative itu, bergantung pada tingkat toleransi individu. Orang bereaksi dengan cara berbeda pada situasi yang sepertinya menghasilkan tuntunan psikologi yang sama. Beberapa 
individu mengatasi secara positif dengan meningkatkan motivasi dan komitmen untuk menyelesaikan pekerjaan (Ivancevich, 2007).

Stres menurut Handoko (2008) merupakan suatu kondisi ketegangan yang mempengaruhi emosi, proses berpikir dan kondisi seseorang. Hasilnya, stres yang terlalu besar dapat mengancam kemampuan seseorang untuk menghadapi lingkungan, yang akhirnya mengganggu pelaksanaan tugas-tugasnya, berarti mengganggu prestasi kerjanya.

Hubungan antara masing-masing perubahan psikologis seorang individu tidak banyak diketahui secara mendetail, tetapi kebanyakan peneliti mengakui bahwa rangsangan psikologis (stressor) termasuk stres akibat pekerjaan merupakan faktor pemicu yang penting untuk timbulnya suatu penyakit tertentu, seperti penyakit jantung, hipertensi, dan beberapa penyakit neuropsikiatris. Stressor sering kali berhubungan langsung dengan sistem tugas, volume pekerjaan dan lingkungan kerja, atau sebagai ketidak harmonisan hubungan dengan individu lain ditempat kerja dan faktor-faktor budaya organisasi tempat kerja (Harrianto, 2009).

Beberapa stressor yang berhubungan pada peranan seseorang di organisasi tempat kerja meliputi sistem tugas sebagai stressor dalam stres kerja di organisasi tempat kerja, yaitu diantaranya kerja lembur / tugas kerja malam. Menurut beberapa penelitian, kerja lembur yang terlalu sering, apalagi bila jumlah jam kerja menjadi berlebihan, ternyata tidak hanya mengurangi kuantitas dan kualitas kerja, tetapi juga sering meningkatkan jumlah absensi dengan alasan sakit atau kecelakaan kerja. Dengan demikian tugas malam merupakan tugas yang berat bagi pekerja, dan sering mengakibatkan timbulnya gangguan fisik akibat kurang tidur serta perubahan tingkah laku yang dapat mendorong individu untuk penyalahgunaan alkohol dan obatobatan terlarang serta perubahan kebiasaan makan.

Kondisi lainnya adalah volume pekerjaan sebagai stressor dalam stres kerja di organisasi tempat kerja, yaitu volume kerja yang berlebihan dan volume kerja yang sangat kurang. Volume pekerjaan yang terlalu banyak akan dibatasi oleh waktu, sehingga sering pekerjaan dilakukan secara tergesa-gesa karena waktu yang terbatas. Sedangkan pada volume kerja yang sangat kurang menyebabkan kurangnya rangsangan untuk bekerja, kurangnya variasi, tidak ada kreativitas atau tuntutan untuk mengatasi masalah.

Penelitian yang dilakukan oleh Taman Prasi (2008) yang meneliti tentang Studi Tentang Stres Kerja pada Masinis Kereta Api Divisi Angkutan Perkotaan Jabotabek 
PT. Kereta Api (Persero), ditemukan tingkat stres kerja ringan sebesar 82,2 \%, stres kerja sedang $17,8 \%$, sedangkan tingkat stress kerja berat tidak ada ditemukan. Tanggung jawab pekerjaan sebagai stressor dalam stres kerja di organisasi tempat kerja, yaitu tanggung jawab untuk keselamatan dan kesejahteraan diri sendiri mencakup tanggung jawab untuk bekerja dengan aman merupakan faktor stres psikis pada pekerja karena harus selalu kerja dengan hati-hati agar tidak membahayakan orang di sekitarnya ataupun membahayakan diri sendiri.

Berdasarkan hasil penelitian dapat diketahui bahwa sebagian besar kepuasan kerja responden dalam kategori tidak puas yaitu sebanyak 54,5\%, dan yang puas sebanyak 45,5\%. Ketidakpuasan kerja ini terjadi lebih sebagai akibat dari padat dan banyaknya tanggung jawab yang diterima oleh masinis selama bekerja. Jadwal kerja yang panjang menyebabkan kelelahan dan rasa kantuk, sehingga banyak keluhan kelelahan dan rasa kantuk ketika akan kembali melakukan aktivitas kerja berikutnya.

Kepuasan kerja adalah suatu respon yang menggambarkan perasaan dari individu terhadap pekerjaannya. Kepuasan kerja adalah kombinasi dari kepuasan kognitif dan efektif individu dalam organisasi. Kepuasan afektif didapatkan dari seluruh penilaian emosional yang positif dari pekerjaan karyawan. Kepuasan afektif ini difokuskan pada suasana hati mereka saat bekerja. Perasaan positif atau suasana hati yang positif mengindikasikan kepuasan kerja. Sedangkan kepuasan kerja kognitif adalah kepuasan yang didapatkan dari penilaian logis dan rasional terhadap kondisi, peluang dan atau "out come". Lebih lanjut Locke dalam Luthans (2006) memberikan penjelasan tentang kepuasan kerja yang meliputi reaksi atau sikap kognitif, afektif, dan evaluatif dan menyatakan bahwa kepuasan kerja adalah "keadaan emosi yang senang atau emosi positif yang berasal dari penilaian pekerjaan atau pengalaman kerja seseorang." Kepuasan kerja adalah hasil dari persepsi karyawan mengenai seberapa baik pekerjaan mereka memberikan hal yang dinilai penting. Secara umum, kepuasan kerjaadalah sikap yang paling penting dan sering dipelajari.

Hasil penelitian menemukan bahwa tingkat kepuasan kerja responden sebagian besar masih rendah, yang dalam hal ini masinis memang masih banyak merasakan kekurangsesuaian dan senang dengan posisi pekerjaan sebagai masinis. Sebagian responden masih berpendapat belum sesuainya antara kompensasi penghasilan dibandingkan dengan beban kerja mereka. Namun secara keseluruhan berdasarkan persepsi responden bahwa tingkat kepuasan kerja mereka rata-rata sudah 
tinggi, disamping kondisi yang ada sudah menunjukkan akan terpenuhinya hak-hak keselamatan dan perlindungan kerja karyawan yang membuat mereka nyaman bekerja.

Penelitian yang dilakukan oleh Tunjungsari (2011) yang meneliti tentang pengaruh stress kerja terhadap kepuasan kerja karyawan pada kantor pusat PT. Pos indonesia (persero) bandung, ditemukan bahwa perhitungan skor total untuk variabel kepuasan kerja karyawan secara total berada dalam kategori Baik dengan mendapat skor $75,0 \%$.

Berdasarkan hasil penelitian menemukan bahwa responden yang stresnya rendah seluruhnya menyatakan kepuasan kerjanya puas yaitu sebanyak 100\%, sementara responden yang stresnya tinggi sebagian besar kepuasan kerjanya menyatakan tidak puas yaitu sebanyak 52,4\%. Stres kerja yang dihadapi masinis terutama berkaitan dengan jadwal kerja serta tanggung jawab terhadap ratusan bahkan ribuan penumpang setiap harinya menyebabkan ketegangan yang luar biasa, sehingga hal ini yang membuat para masinis merasakan kekurangpuasan terhadap pekerjaannya tersebut. Terlebih lagi banyaknya kasus kecelakaan kereta yang terjadi menambah tingkat ketegagan setiap kali harus menjalankan kereta hingga sampai tujuan dengan selamat dan penuh tanggung jawab. Berdasarkan uji chi square didapatkan nilai p sebesar 0,000 $<0,05$ sehingga dinyatakan ada hubungan yang bermakna antara tingkat stress dengan kepuasan kerja pada masinis PT Kereta Api Indonesia di UPT Crew Semarang Poncol. Hasil penelitian ini sesuai dengan penelitian yang dilakukan oleh Anitawidanti (2010) yang menemukan bahwa ada hubungan antara stress kerja dengan kepuasan kerja. Hal ini menunjukkan bahwa masing-masing variabel stres kerja memiliki hubungan positif dengan variabel kepuasan kerja, yang berarti bahwa jika stres kerja meningkat maka kepuasan kerja juga meningkat.

Ditinjau dari gejala psikologis, stres dapat menyebabkan ketidakpuasan. Stres yang berkaitan dengan pekerjaan dapat menimbulkan ketidakpuasan yang berkaitan dengan pekerjaan. Itulah "dampak psikologis yang paling sederhana dan paling jelas" dari stres. Stres juga dapat muncul dalam keadaan psikologis lain, misalnya ketegangan, kecemasan, mudah marah, kebosanan, dan suka menundanunda, terbukti bahwa bila orang ditempatkan dalam pekerjaan yang mempunyai tuntutan ganda dan berkonflik atau di tempat yang tidak ada 
kejelasan mengenai tugas, wewenang, dan tanggungjawab pemikul pekerjaan, stres dan ketidakpuasan kerja akan meningkat. Semakin sedikit kendali yang dipegang orang atas kecepatan kerja mereka, makin besar stres dan ketidakpuasan. Walaupun diperlukan lebih banyak riset untuk memperjelas hubungan itu, bukti mengemukakan bahwa pekerjaan-pekerjaan yang memberikan keragaman, nilai penting, otonomi, umpan balik, dan identitas pada tingkat yang rendah ke pemangku pekerjaan akan menciptakan stres dan mengurangi kepuasan serta keterlibatan dalam pekerjaan itu ((Robbins, 2007)..

\section{Kesimpulan}

Berdasarkan hasil penelitian dan pembahasan pada bab sebelumnya maka dapat disimpulkan sebagai berikut :

1. Tingkat stres kerja yang dialami oleh responden sebagian besar adalah tinggi yaitu sebanyak $67,1 \%$.

2. Kepuasan kerja responden sebagian besar dalam kategori tidak puas yaitu sebanyak 78 orang $(54,5 \%)$.

3. Ada hubungan antara tingkat stress dengan kepuasan kerja pada masinis PT Kereta Api Indonesia di UPT Crew Semarang Poncol

\section{Saran}

\section{Profesi Keperawatan}

Hasil penelitian menemukan bahwa stres kerja berhubungan dengan kepuasan kerja. Oleh karena itu disarankan kepada profesi keperawatan yang bekerja di Unit Kesehatan Kereta Api dapat mengurangi stressor terjadinya stress seperti mengajarkan teknik rilaksasi terhadap masinis sehingga mampu mengurangi ketegangan akibat pekerjaan. Proses keperawatan ini juga diharapkan dapat memberikan pendidikan kesehatan kepada masinis tentang tata cara mengurangi stres kerja.

\section{PTKAI}

PTKAI diharapkan dapat menambah jumlah masinis dengan pola shift kerja yang longgar sehingga masinis memiliki waktu isirahat yang cukup untuk mengurangi stress akibat jadwal kerja yang padat. 
3. Penelitian Selanjutnya

Peneliti selanjutnya yang melakukan penelitian sejenis diharapkan dapat melakukan penelitian dengan menggunakan metode penelitian kualitatif melalui wawancara mendalam sehingga dapat diketahui factor penyebab stress lebih mendalam.

\section{DAFTAR PUSTAKA}

Arikunto, Suharsini. 2006. "Prosedur Penelitian”. Pendekatan Praktek. Rineka Cipta: Jakarta.

As'ad, Moh, 2007. Psikologi Industri. Liberty: Yogyakarta.

Ghozali, Imam. 2006. Aplikasi Analisis Multivariate Dengan Program SPSS. Badan Penerbit UNDIP: Semarang

Handoko, Hani T, 2008, "Manajemen Sumber Daya Manusia", BPFE: Yogyakarta

Hasan, I. (2008). Analisis Data Penelitian Dengan Statistik. Jakarta : Bumi Aksara.

Hastono, S.P. (2013). Analisa Data Kesehatan. Jakarta: Universitas Indonesia

Hidayat. A.A.A. 2007. Metode Penelitian Keperawatan dan Tekhnik Analisa Data. Jakarta: Salemba Medika

Kreitner, Robert, Kinicki, Angelo. 2007.

Organizational Behavior. 7th ed. McGraw-Hill Inc. New York.

Luthans, Fred. 2006. Perilaku Organisasi, (Alih Bahasa V.A Yuwono, dkk),Edisi Bahasa Indonesia, Yogyakarta: ANDI.

Mas'ud, Fuad (2006). 40 Mitos Manajemen Sumber Daya Manusia. Semarang: Badan Penerbit Universitas Diponegoro

Munandar, Bertina Sjabadhyni, Rufus Patty Wutun, 2008. Peran Budaya Organisasi dalam Peningkatan Unjuk Kerja Perusahaan. Fakultas Psikologi Universitas Indonesia, Jakarta.

Notoatmodjo, S. 2010. Metodologi Penelitian Kesehatan. Jakarta: Rineka Cipta.

Robbins. Stephens P, 2007, Perilaku Organisasi-Konsep Kontroversi, Aplikasi, Edisi Bahasa Indonesia, Jilid 1 dan 2, Prenhallindo, Jakarta.

Saifuddin Azwar, MA, 2003, Metode Penelitian, Pustaka Pelajar, Yogyakarta

Setyawati. 2010. Selintas Tentang Kelelahan Kerja. Yogyakarta: Asmara Books

Stranks, J. (2007). The Handbookof Health and Safety Practices. New Jersey: Pearson Education

Sugiyono, 2007, Metode Penelitian Bisnis.Bandung: Penerbit Alfabeta.

Tunjungsari, P. (2011). Pengaruh stress kerja terhadap kepuasan kerja karyawan pada kantor pusat PT. Pos Indonesia (Persero) Bandung. Jurnal. Vol. 1 No. 1, Maret 2011 